\title{
Article
}

\section{The Relationship between Alexithymia, Dysmorphic Concern, and Exercise Addiction: The Moderating Effect of Self-Esteem}

\author{
Alessio Gori ${ }^{1,2, *}$, Eleonora Topino ${ }^{3}{ }^{(}$, Caterina Pucci $^{1}$ and Mark D. Griffiths ${ }^{4}(\mathbb{C}$ \\ 1 Department of Health Sciences, University of Florence, Via di San Salvi 12, Pad. 26, 50135 Florence, Italy; \\ caterina.pucci@stud.unifi.it \\ 2 Integrated Psychodynamic Psychotherapy Institute (IPPI), via Ricasoli 32, 50122 Florence, Italy \\ 3 Department of Human Sciences, LUMSA University of Rome, Via della Traspontina 21, 00193 Rome, Italy; \\ eleonora.topino@gmail.com \\ 4 Psychology Department, Nottingham Trent University, 50 Shakespeare Street, Nottingham NG1 4FQ, UK; \\ mark.griffiths@ntu.ac.uk \\ * Correspondence: Correspondence: alessio.gori@unifi.it
}

Citation: Gori, A.; Topino, E.; Pucci, C.; Griffiths, M.D. The

Relationship between Alexithymia, Dysmorphic Concern, and Exercise Addiction: The Moderating Effect of Self-Esteem. J. Pers. Med. 2021, 11, 1111. https://doi.org/10.3390/ jpm11111111

Academic Editor: Marco Costanzi

Received: 11 October 2021

Accepted: 28 October 2021

Published: 29 October 2021

Publisher's Note: MDPI stays neutral with regard to jurisdictional claims in published maps and institutional affiliations.

\begin{abstract}
As with other addictions, exercise addiction can severely impact individuals' lives and have significant psychophysical consequences. Consequently, the study of the mechanisms involved in this psychopathological condition has great clinical and practical relevance. Therefore, the goal of the present study was to explore the risk factors and protective factors for exercise addiction, with a particular focus on the roles of alexithymia, body image concerns, and self-esteem. A sample of 288 regular exercisers (mean age $=28.35$ years, $\mathrm{SD}=8.26 ; 72 \%$ females, $18 \%$ males) completed the Exercise Addiction Inventory, 20-Item Toronto Alexithymia Scale, Body Image Concern Inventory, and Rosenberg Self-Esteem Scale. Data were analyzed by implementing a moderated mediation model. Results showed a significant and positive association between alexithymia and exercise addiction, totally mediated by body image concerns. Furthermore, self-esteem showed a relevant moderating effect, such that at high levels of self-esteem the effect of alexithymia on body image concerns became insignificant. Such data have important implications, highlighting some core variables on which it might be useful to keep a focus in order to elaborate tailored interventions, from both preventive and treatment perspectives.
\end{abstract}

Keywords: exercise addiction; alexithymia; emotional dysregulation; body image; self-esteem

\section{Introduction}

A large body of research has shown that physical activity-defined as any body movement that requires energy expenditure [1] — has positive effects on physical and mental health [2]. Recommendations for the minimum level of physical activity that is needed for beneficial health effects have been provided by the World Health Organization [3], with parameters based on age and physical condition. Specifically, the recommendation for people aged 18-64 years without chronic conditions or disabilities, and not in a pre/postpartum state, is at least 150-200 min of moderate-intensity aerobic physical activity, at least 75-150 min of vigorous-intensity aerobic physical activity, or an equivalent combination of these activities, per week [3]. However, when exercise becomes excessive, it can lead to the implementation of compulsive training patterns that can evolve into a pathology-so-called "exercise addiction" [4].

Some authors define exercise addiction as a morbid behavior in which individuals gradually lose control over their exercise habits, act compulsively, and experience negative consequences - both physically, and in their social and/or professional lives [5,6]. Physical damage is manifested predominantly through long-term risks such as musculoskeletal injuries and psychological damage (typically expressed through immediate changes in mood, such as the feeling of depression when the individual cannot exercise) [6,7]. More 
specifically, the symptoms and consequences of exercise addiction have been characterized by six common components of addiction: salience, mood modification, tolerance, withdrawal symptoms, personal conflict, and relapse [8,9]. In the event of addiction, the negative consequences are ignored, and do not prevent individuals from continuing to exercise $[9,10]$. Investigations of these factors have been helpful to the field from both preventive and treatment perspectives [11,12]. Therefore, the present study explores the interaction of risk factors and protective factors in pathways towards exercise addiction among regular exercisers, with a particular focus on the roles of alexithymia, body image concerns, and self-esteem.

Alexithymia, a construct originally introduced by Sifneos [13], is a specific form of emotional dysregulation that is defined by a difficulty in identifying, describing, and verbalizing emotions, as well as difficulty by individuals in discriminating their own emotional experiences from underlying physiological activation, which is also characterized by constricted imaginary processes [14-16]. It appears that psychic suffering resulting from affective dysregulation can lead those with alexithymia to regulate their negative emotions through behaviors that may be a risk to their health (e.g., drug use, engaging in risky sports, eating disorders) [17-19]. Therefore, it is not surprising that many scientific studies have shown a relationship between alexithymia and substance dependence $[17,20]$ and behavioral addictions [21-23], including that related to exercise addiction.

The relationship between alexithymia and exercise addiction has been examined in different populations of exercisers, such as those attending fitness centers [24], swimmers [25], and sports university students [26]. Some research has suggested that the use of physical activity could be a means by which these individuals try to suppress their unmentalized emotional states, as a form of dissociation from painful experiences $[17,24]$. An interesting point of view is provided by some research arguing that the inability to symbolize emotional experiences—as well as the resulting undifferentiated and dysregulated affect-may also lead to body image distortion [27]. In other words, the inability of an individual to discriminate between emotional states and bodily sensations can increase dissatisfaction with their body, and could lead to a wrong interpretation of the perceptual and behavioral aspects of their body image [28]. Such inability could indeed arouse an emotional void that leads individuals to focus excessively on the details of their own body. This, in turn, can result in the use of maladaptive strategies (including excessive exercise) in order to control the body and physical appearance [26], as found in some cases of body dysmorphic disorder (BDD) [27].

On this basis, it is important to emphasize the associations between body concerns and exercise addiction. Several studies (e.g., [29,30]) have found different psychopathological conditions that co-occur with exercise addiction; among these, BDD is a severe psychiatric condition characterized by a recurring and persistent concern with an imagined or minor defect in physical appearance, with a focus on a specific body part [29]. In fact, individuals showing excessive concern over body image and weight are among those most likely to experience exercise addiction [31]. Some other studies have suggested that preoccupation with body image may be a driving force underlying exercise addiction [32]. Indeed, this dissatisfaction may lead to the search for a transformation of the perceived body image into an "ideal body image", through inadequate nutritional planning and excessive physical exercise. Consequently, physical exercise could become a vehicle to improve body image, as opposed to being motivated by the desire for increased health and wellbeing [29].

Within this framework, self-esteem could also be a relevant factor, since lower levels of self-esteem can influence the ways individuals perceive their own bodies [33,34]. Scientific literature agrees that self-esteem plays a central role in individuals' mental health, and it is more likely that a positive self-image and a strong sense of self-esteem help individuals to become more satisfied with their bodies [35]. In fact, higher self-esteem may protect the individual from the negative feelings related to their body weight, and from anxiety arising from the negative judgments of others [36-38], showing a beneficial influence on bodyimage-related preoccupation [35,39]. On the other hand, individuals with low self-esteem 
appear to be more vulnerable to comments concerning their bodies, and more dissatisfied with physical aspects of their bodies over time $[36,40]$. Previous evidence suggests that increased self-esteem could play a protective role against body image concerns [41].

Given this evidence, the present study examined the role of alexithymia, body image concerns, and self-esteem in exercise addiction, by testing a moderated mediation model among a sample of regular exercisers. More specifically, it was hypothesized that body image concerns would mediate the relationship between alexithymia and exercise addiction, with self-esteem moderating the relationship between alexithymia and body image concerns (see Figure 1A).

A)

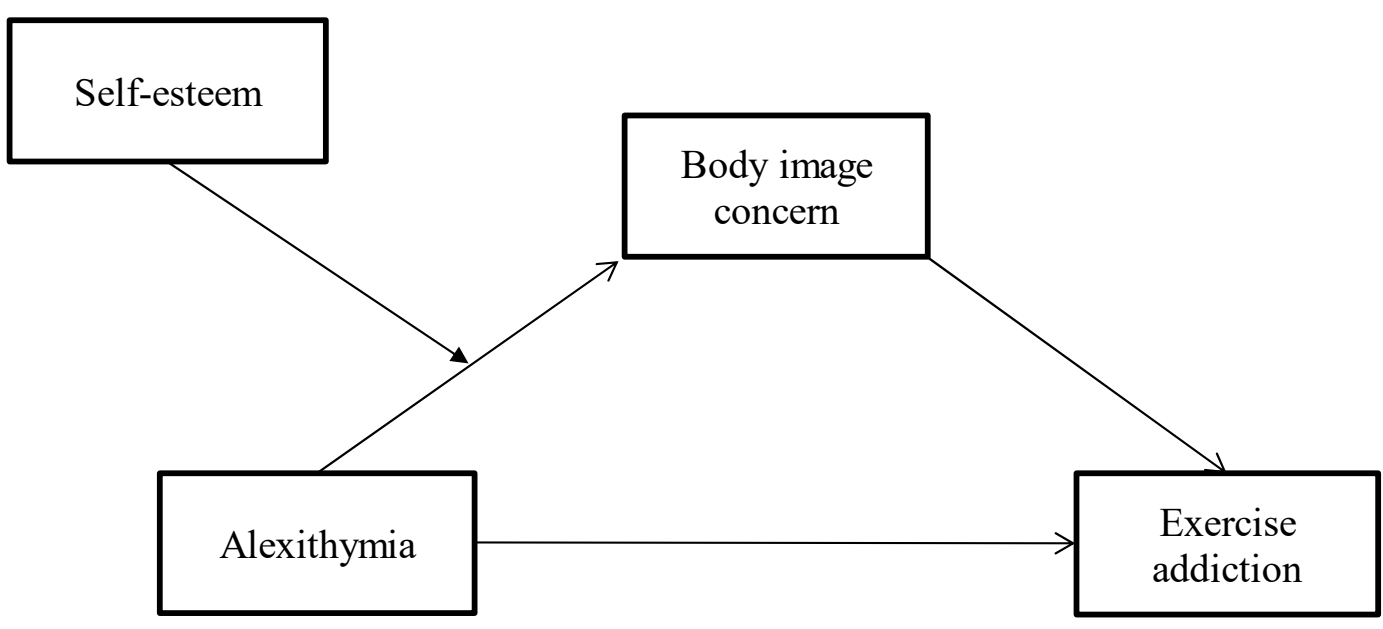

B)

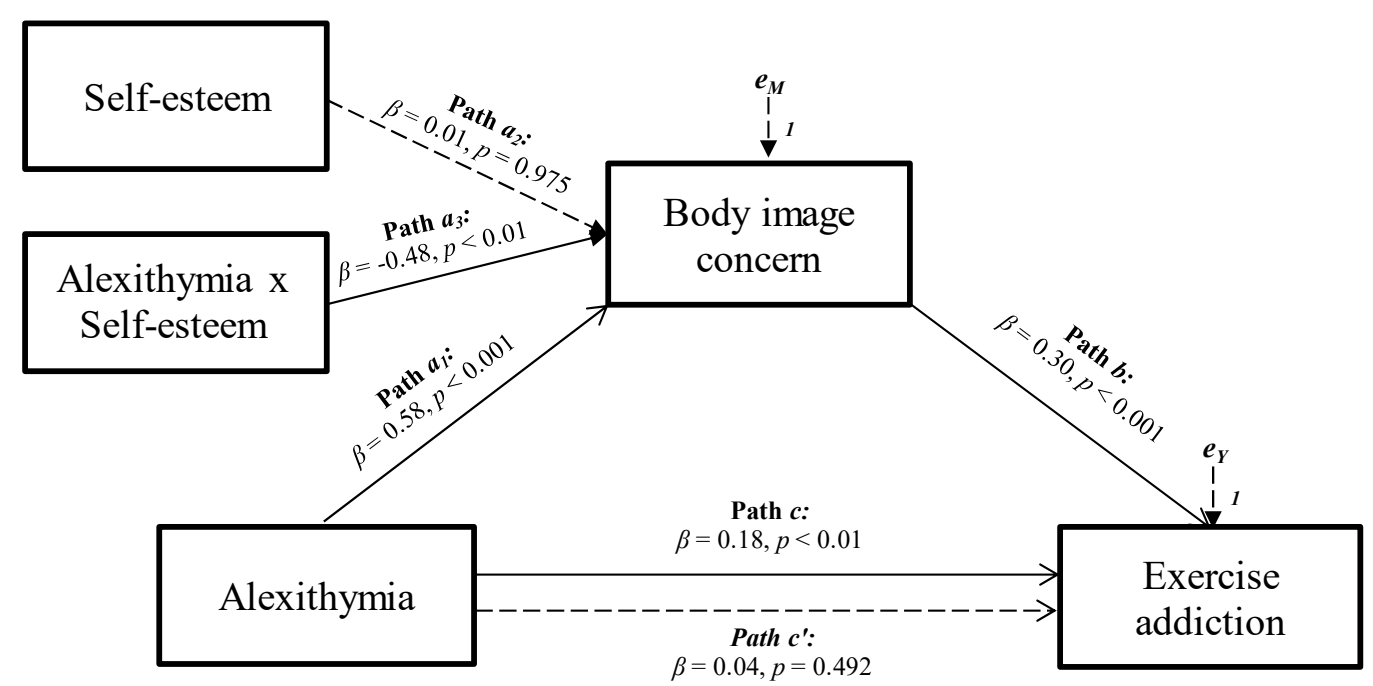

Figure 1. Statistical (A) and conceptual (B) forms of the moderated mediation model involving alexithymia, body image concerns, self-esteem, and exercise addiction.

\section{Materials and Methods}

\subsection{Participants, Procedure, and Ethics}

The sample comprised 288 Italian participants who declared that they regularly engaged in exercise (i.e., at least three times per week for a minimum of 30 min each session). Their age ranged from 19 to 53 years $\left(M_{\text {age }}=28.35\right.$ years, $\left.S D=8.26\right)$, and they were predominantly females (72\%). As shown in Table 1, most of the participants declared that they were single $(75 \%)$, had a high school diploma $(46 \%)$, and were students (35\%).

All of the participants were recruited online. The study was advertised on the authors' various social networks, with a recruitment message that included an anonymous link to the survey. Therefore, the survey was further distributed utilizing a snowball sampling 
method. The participants voluntarily took part in the study by completing a self-report survey hosted on the Google Forms platform, after they had been informed about the general aims of the research and provided informed consent electronically. The protocol of the present study was approved by the Ethical Committee of the Integrated Psychodynamic Psychotherapy Institute (IPPI) (ethical approval number 004/2021).

Table 1. Demographic characteristics of the sample $(N=288)$.

\begin{tabular}{|c|c|c|c|c|}
\hline Characteristics & & $M \pm S D$ & $n$ & $\%$ \\
\hline Age (years) & & $28.4 \pm 8.26$ & & \\
\hline \multicolumn{5}{|l|}{ Sex } \\
\hline & Females & & 206 & 71.5 \\
\hline & Males & & 82 & 28.5 \\
\hline \multicolumn{5}{|l|}{ Marital Status } \\
\hline & Single & & 215 & 74.7 \\
\hline & Married & & 25 & 8.7 \\
\hline & Cohabiting & & 39 & 13.5 \\
\hline & Separated & & 4 & 1.4 \\
\hline & Divorced & & 4 & 1.4 \\
\hline & Widowed & & 1 & 0.3 \\
\hline \multicolumn{5}{|l|}{ Education } \\
\hline & Middle school diploma & & 8 & 2.8 \\
\hline & High school diploma & & 132 & 45.8 \\
\hline & University degree & & 86 & 29.9 \\
\hline & Master's degree & & 43 & 14.9 \\
\hline & Post-lauream specialization & & 19 & 6.6 \\
\hline \multicolumn{5}{|l|}{ Occupation } \\
\hline & Student & & 98 & 34.0 \\
\hline & Working student & & 58 & 20.1 \\
\hline & Employee & & 78 & 27.1 \\
\hline & Freelance & & 18 & 6.3 \\
\hline & Entrepreneur & & 12 & 4.2 \\
\hline & Trader & & 8 & 2.8 \\
\hline & Artisan & & 3 & 1.0 \\
\hline & Armed forces & & 1 & 0.3 \\
\hline & Unemployed & & 11 & 3.8 \\
\hline & Retired & & 1 & 0.3 \\
\hline
\end{tabular}

\subsection{Measures}

Exercise Addiction Inventory (EAI): The EAI [9,42] is a self-report measure that assesses the risk of exercise addiction. The six items (e.g., "If I have to miss an exercise session, I feel moody and irritable") were developed using the components model of behavioral addiction (Griffiths, 1996), and comprise the dimensions of salience, mood modification, tolerance, withdrawal symptoms, conflict, and relapse. Items are scored on a five-point Likert scale from 1 (strongly disagree) to 5 (strongly agree). The total scores range from 6 to 30, with higher scores indicating more problematic exercise for the individual. A cutoff score for individuals considered at risk of exercise addiction is 24 , while a score of 13-23 indicates a symptomatic individual, and a score of $0-12$ suggests an asymptomatic individual [9]. Cronbach's alpha value for the Italian version [43] used in the present study was $\alpha=0.71$.

Twenty-Item Toronto Alexithymia Scale (TAS-20): The TAS-20 [14,15] is a self-report measure that assesses alexithymia. The 20 items of the TAS-20 are scored on a five-point Likert scale from 1 ("strongly disagree) to 5 (strongly agree) and comprising three subscales: difficulty identifying feelings (e.g., "I am often confused about what emotion I am feeling"), difficulty describing feelings (e.g., "It is difficult for me to find the right words for my feelings"), and externally oriented thinking (e.g., "I prefer to analyze problems rather than just describe them"). Cronbach's alpha value for the Italian version [44] used in the present study was $\alpha=0.75$ for the total scale. 
Body Image Concern Inventory (BICI): The BICI [45] is a self-report measure that assesses dysmorphic body image concerns. The 19 items of the BICI are scored on a five-point Likert scale from 1 (never) to 5 (always) and comprising two subscales: dysmorphic symptoms (e.g., "I am dissatisfied with some aspect of my appearance"), and symptom interference (e.g., "I have missed social activities because of my appearance"). Cronbach's alpha value for the Italian version [46] used in the present study was $\alpha=0.91$ for the total scale.

Rosenberg Self-Esteem Scale (RSES): The RSES [47] is a self-report measure that assesses self-esteem. The 10 items of the RSES are scored on a four-point Likert scale from 0 (strongly disagree) to 3 (strongly agree). Cronbach's alpha value for the Italian version [48] used in the present study was $\alpha=0.84$.

\subsection{Data Analysis}

Data were analyzed using SPSS for Windows (v. 21). A two-sided value of $p<0.01$ was the level of statistical significance in the present study. There were no missing values in the dataset because the online platform used did not allow the submission of surveys unless all items were answered. Descriptive statistics for the sample and the study measures were carried out. A Pearson's $r$ correlation analysis was performed to investigate the associations between the variables, together with the coefficient of determination $\left(\mathrm{R}^{2}\right)$. According to Cohen [49], values of $0.25,0.09$, and 0.01 correspond to large, moderate, or small relationships, respectively. The hypothesized moderated mediation model was tested through the macro-program PROCESS 3.4 [50], by performing Model 7. For completeness, the potential confounding role of age was also explored in the model. The $95 \%$ confidence interval (CI) was calculated for each regression coefficient, such that when the 95\% CI (from LLCI to ULCI) does not contain the zero, the effect should be considered significant. The conditional indirect effect was evaluated following Wayne et al.'s [51] procedure, by analyzing the index of the moderated relationship at three different levels of the moderator (-1DS, Mean, +1DS). Furthermore, a bootstrapping procedure with $95 \%$ CI at 5000 samples was used to confirm the statistical significance of the moderation effect. When the bootstrapped confidence interval (from boot LLCI to boot ULCI) does not contain the zero, the effect should be considered significant.

\section{Results}

Descriptive statistics are reported in Tables 1 and 2. Pearson's $r$ analysis (see Table 2) showed that the highest correlation was between exercise addiction and body image concern $(r=0.317, p<0.01)$, explaining 30\% of the variance. Furthermore, there were significant positive correlations between exercise addiction and age $(r=0.153, p<0.01)$ and exercise addiction and alexithymia $(r=0.178, p<0.01)$. There was a significant negative correlation between exercise addiction and self-esteem $(r=-0.152, p<0.01)$. In turn, self-esteem was significantly negatively correlated with body image concerns $(r=-0.608, p<0.01)$ and alexithymia $(r=-0.512, p<0.01)$ scores. Body image concerns and alexithymia were significantly positively correlated $(r=0.454, p<0.01)$.

The moderated mediation analysis showed that body image concerns totally mediated the relationship between alexithymia and exercise addiction, and the association between alexithymia and body image concerns was moderated by self-esteem (see Figure 1).

More specifically, the total effect of alexithymia on exercise addiction was significant and positive (Path $c$ in Figure 1B; $\beta=0.18, p<0.01, \mathrm{LLCI}=0.0217-\mathrm{ULCI}=0.0997$ ). Alexithymia was also significantly and positively associated with body image concerns, the mediator variable (Path $a_{1}$ in Figure $1 \mathrm{~B} ; \beta=0.58, p<0.001, \mathrm{LLCI}=0.3846-\mathrm{ULCI}=1.1129$ ). Body image concerns showed a significant and positive relationship with exercise addiction (Path $b$ in Figure 1B; $\beta=0.30, p<0.001$, LLCI $=0.0458-U L C I=0.1115$ ) and, when included in the model, totally mediated the association between alexithymia and exercise addiction (see Model 1a in Table 3), which became insignificant (Path $c^{\prime}$ in Figure 1B; $\beta=0.04$, $p=0.492$, LLCI $=-0.0275-\mathrm{ULCI}=0.0570$ ). Furthermore, self-esteem was found to be a significant moderator in the relationship between alexithymia and body image concerns 
(Path $a_{3}$ in Figure 1B; $\beta=-0.48, p<0.01, \mathrm{LLCI}=-0.0413-\mathrm{ULCI}=-0.0079$ ): $\Delta R^{2}=0.017$, $F(1,285)=6.810, p<0.01$ (index of moderated mediation $=-0.0019$, Boot LLCI $=-0.0037$ - Boot ULCI $=-0.0007)$.

Table 2. Pearson's correlation, means, and standard deviations of the study variables.

\begin{tabular}{|c|c|c|c|c|c|c|c|c|c|}
\hline & 1 & 2 & 3 & 4 & 5 & 6 & 7 & 8 & 9 \\
\hline 1. EAI & 1 & & & & & & & & \\
\hline $\begin{array}{l}\text { 2. TAS-20 } \\
\left(\mathrm{R}^{2}\right)\end{array}$ & $\begin{array}{c}\mathbf{0 . 1 7 8} * * \\
(0.032)\end{array}$ & 1 & & & & & & & \\
\hline $\begin{array}{l}\text { 3. TAS-20 (F1) } \\
\left(\mathrm{R}^{2}\right)\end{array}$ & $\begin{array}{c}\mathbf{0 . 1 6 3} * * \\
(0.027)\end{array}$ & $\begin{array}{c}\mathbf{0 . 8 0 3} * * \\
(0.645)\end{array}$ & 1 & & & & & & \\
\hline $\begin{array}{l}\text { 4. TAS-20 (F2) } \\
\qquad\left(\mathrm{R}^{2}\right)\end{array}$ & $\begin{array}{c}\mathbf{0 . 2 1 4} * * \\
(0.046)\end{array}$ & $\begin{array}{c}\mathbf{0 . 8 4 4} * * \\
(0.712)\end{array}$ & $\begin{array}{c}\mathbf{0 . 5 5 6} \text { ** } \\
(0.309)\end{array}$ & 1 & & & & & \\
\hline $\begin{array}{c}\text { 5. TAS-20 (F3) } \\
\left(\mathrm{R}^{2}\right)\end{array}$ & $\begin{array}{c}0.006 \\
(0.000)\end{array}$ & $\begin{array}{c}\mathbf{0 . 5 8 5} * * \\
(0.342)\end{array}$ & $\begin{array}{c}\mathbf{0 . 2 7 9} * * \\
(0.078)\end{array}$ & $\begin{array}{c}\mathbf{0 . 2 1 1} * * \\
(0.045)\end{array}$ & 1 & & & & \\
\hline $\begin{array}{l}\text { 6. RSES } \\
\left(\mathrm{R}^{2}\right)\end{array}$ & $\begin{array}{c}-\mathbf{0 . 1 5 2} * * \\
(0.023)\end{array}$ & $\begin{array}{c}-0.512 * * \\
(0.262)\end{array}$ & $\begin{array}{c}-0.397^{* *} \\
(0.158)\end{array}$ & $\begin{array}{c}-\mathbf{0 . 5 5 9} * * \\
(0.312)\end{array}$ & $\begin{array}{c}-\mathbf{0 . 1 3 7} * \\
(0.019)\end{array}$ & 1 & & & \\
\hline $\begin{array}{l}\text { 7. BICI } \\
\left(\mathrm{R}^{2}\right)\end{array}$ & $\begin{array}{c}\mathbf{0 . 3 1 7}^{* *} \\
(0.100)\end{array}$ & $\begin{array}{c}\mathbf{0 . 4 5 4} * * \\
(0.206)\end{array}$ & $\begin{array}{c}\mathbf{0 . 3 3 1}^{* *} \\
(0.110)\end{array}$ & $\begin{array}{c}\mathbf{0 . 5 3 8} * * \\
(0.289)\end{array}$ & $\begin{array}{c}0.091 \\
(0.008)\end{array}$ & $\begin{array}{c}-\mathbf{0 . 6 0 8} * * \\
(0.370)\end{array}$ & 1 & & \\
\hline $\begin{array}{l}\text { 8. BICI (F1) } \\
\left(\mathrm{R}^{2}\right)\end{array}$ & $\begin{array}{c}\mathbf{0 . 3 0 5} * * \\
(0.093)\end{array}$ & $\begin{array}{c}\mathbf{0 . 4 4 9} * * \\
(0.202)\end{array}$ & $\begin{array}{c}\mathbf{0 . 3 4 3} * * \\
(0.118)\end{array}$ & $\begin{array}{c}\mathbf{0 . 5 3 1} * * \\
(0.282)\end{array}$ & $\begin{array}{c}0.078 \\
(0.006)\end{array}$ & $\begin{array}{c}-\mathbf{0 . 5 9 8} * * \\
(0.358)\end{array}$ & $\begin{array}{c}\mathbf{0 . 9 9 0} * * \\
(0.980)\end{array}$ & 1 & \\
\hline $\begin{array}{c}\text { 9. } \mathrm{BICI}(\mathrm{F} 2) \\
\left(\mathrm{R}^{2}\right)\end{array}$ & $\begin{array}{c}\mathbf{0 . 2 9 8} * * \\
(0.089)\end{array}$ & $\begin{array}{c}\mathbf{0 . 3 8 2} * * \\
(0.146)\end{array}$ & $\begin{array}{c}\mathbf{0 . 2 1 8} * * \\
(0.048)\end{array}$ & $\begin{array}{c}\mathbf{0 . 4 5 7} * * \\
(0.209)\end{array}$ & $\begin{array}{l}\mathbf{0 . 1 2 6} \text { * } \\
(0.016)\end{array}$ & $\begin{array}{c}-0.525 * * \\
(0.276)\end{array}$ & $\begin{array}{c}\mathbf{0 . 8 3 7} * * \\
(0.701)\end{array}$ & $\begin{array}{c}\mathbf{0 . 7 5 1} * * \\
(0.564)\end{array}$ & 1 \\
\hline 10. Age & $0.153 * *$ & $-0.175 * *$ & $-0.151 *$ & $-0.173 * *$ & -0.073 & $0.191^{* *}$ & -0.104 & -0.128 * & 0.012 \\
\hline $\begin{array}{c}\left(\mathrm{R}^{2}\right) \\
M\end{array}$ & $\begin{array}{l}(0.023) \\
17.510\end{array}$ & $\begin{array}{l}(0.031) \\
47.656\end{array}$ & $\begin{array}{l}(0.023) \\
13.736\end{array}$ & $\begin{array}{l}(0.030) \\
16.618\end{array}$ & $\begin{array}{l}(0.005) \\
35.014\end{array}$ & $\begin{array}{l}(0.036) \\
20.406\end{array}$ & $\begin{array}{l}(0.011) \\
47.781\end{array}$ & $\begin{array}{l}(0.016) \\
40.903\end{array}$ & $\begin{array}{c}(0.000) \\
6.878\end{array}$ \\
\hline$S D$ & 4.446 & 13.061 & 5.091 & 6.924 & 4.401 & 7.006 & 16.795 & 13.927 & 3.595 \\
\hline
\end{tabular}

Note: Bold values indicate significant $p$-values. ${ }^{* *}$ : Correlation is significant at the $p<0.01$ level (2-tailed); ${ }^{*}$ : correlation is significant at the $p<0.05$ level (2-tailed). EAI: Exercise Addiction Inventory; TAS-20: 20-Item Toronto Alexithymia Scale; TAS-20 (F1): difficulty describing feelings (20-Item Toronto Alexithymia Scale); TAS-20 (F2): difficulty identifying feelings (20-Item Toronto Alexithymia Scale); TAS-20 (F3): externally oriented thinking (20-Item Toronto Alexithymia Scale); RSES: Rosenberg Self-Esteem Scale; BICI: Body Image Concern Inventory; BICI (F1): dysmorphic symptoms (Body Image Concern Inventory); BICI (F2): symptom interference (Body Image Concern Inventory).

The conditional indirect effect was evaluated by analyzing the index of the moderated relationship at three different levels of the moderator (-1DS, Mean, +1DS). The association between alexithymia and body image concerns was slightly stronger at low levels of selfesteem (estimate $=0.419[0.10], p<0.001, \mathrm{LLCI}=0.2425-\mathrm{ULCI}=0.5958)$ than at average levels (estimate $=0.246[0.07], p<0.001$, LLCI $=0.1131-\mathrm{ULCI}=0.3806$ ), and became insignificant at high levels (estimate $=0.075[0.09], p=0.822, \mathrm{LLCI}=-0.1039-\mathrm{ULCI}=0.2529$ ). Therefore, when participants reported higher levels of self-esteem, the positive indirect effect of alexithymia on exercise addiction via body image concerns weakened to become insignificant: effect $=0.0059(0.0068)$, BootLLCI $=-0.0085$ - BootULCI $=0.0183$ (see Figure 2).

Finally, the statistical significance of the moderation effect was confirmed via the bootstrapping procedure, since the bootstrapped confidence interval did not contain the zero: Boot LLCI $=-0.0421-$ Boot ULCI $=-0.0098$.

The potential confounding of age was also examined. Age showed a significant covariant effect on exercise addiction for both the indirect effect of alexithymia on exercise addiction via the mediation of body image concern, and the moderation of body image concern $(\beta=0.20, p<0.001$, Boot LLCI $=0.0547-$ Boot ULCI $=0.1594)$, as well as for the total effect $(\beta=0.19, p<0.01$, Boot LLCI $=0.0444$-Boot ULCI $=0.1621)$. Moreover, controlling for age, both the total effect of alexithymia on exercise addiction $(\beta=0.21$, $p<0.001, \mathrm{LLCI}=0.0331-\mathrm{ULCI}=0.1110$ ) and the moderated mediation model (see Model $1 \mathrm{~b}$ in Table 3) remained statistically significant. 

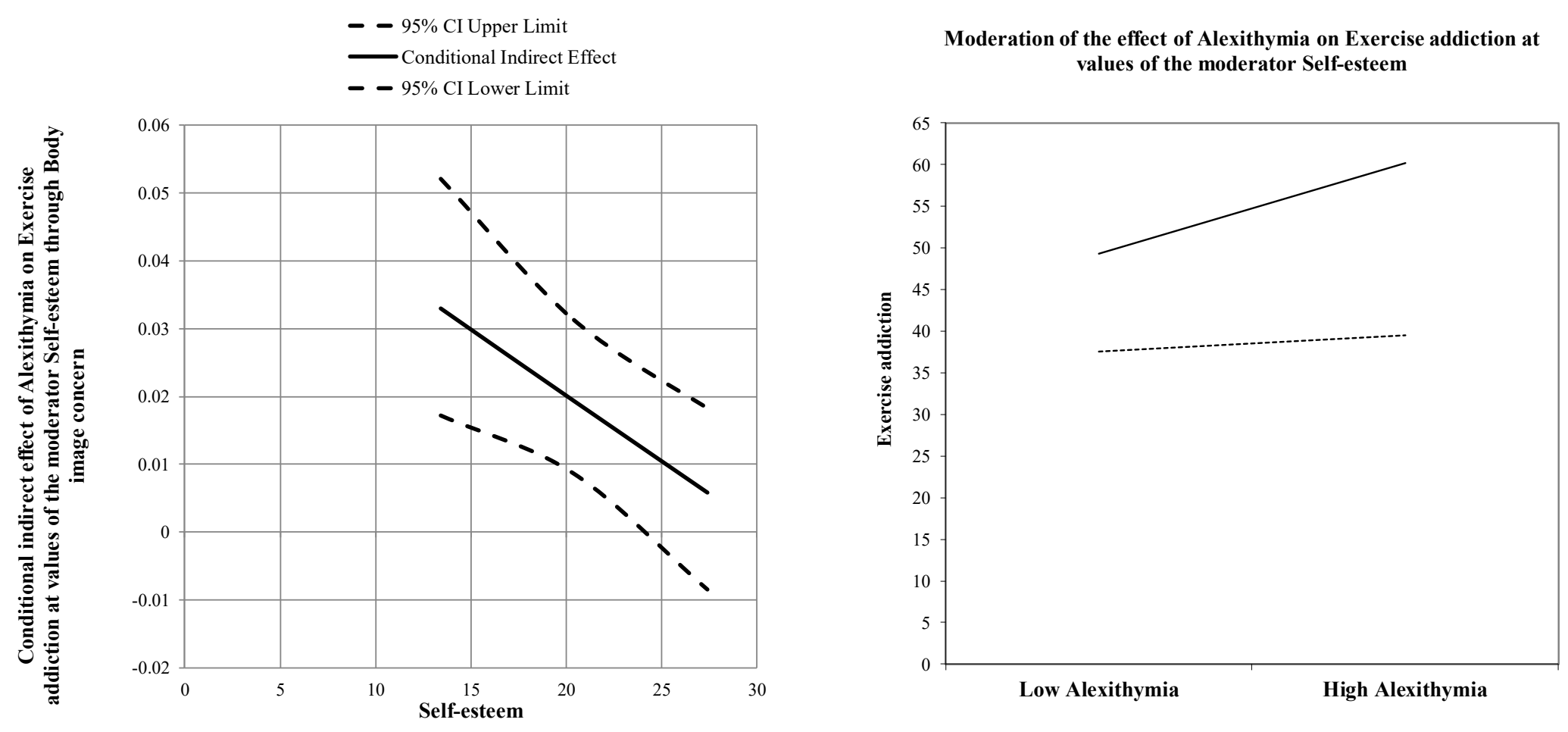

------- High Self-esteem

L Low Self-esteem

Figure 2. Graphical representation of the moderation effect. 
Table 3. Coefficients of the models.

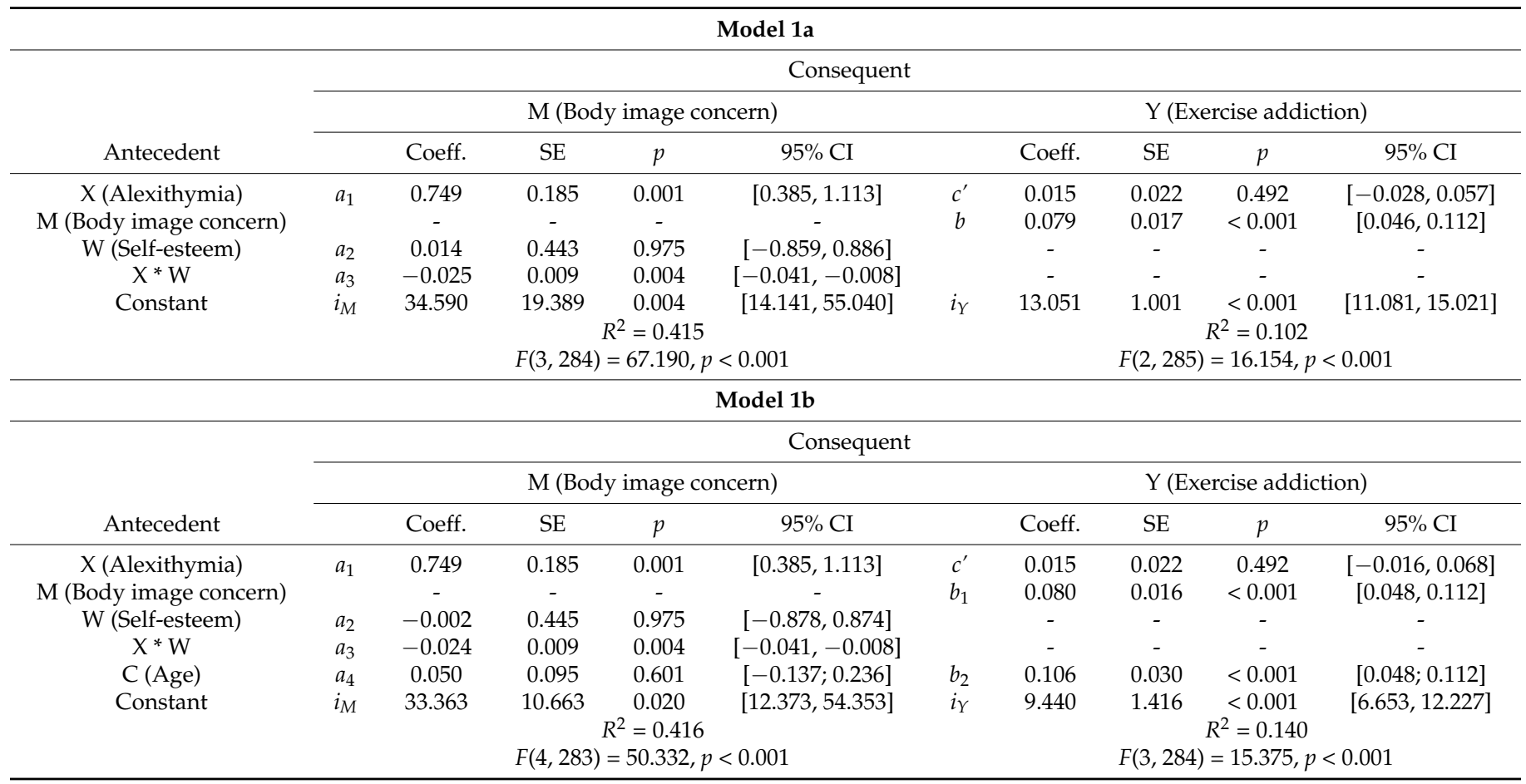

Note: Model 1a: the relationship between alexithymia and exercise addiction, with body image concern as mediator and self-esteem as moderator; Model 1b: the relationship between alexithymia and exercise addiction, with body imageconcern as mediator, self-esteem as moderator, and age as covariate.

\section{Discussion}

The physical, psychological, aesthetic, and social benefits of regular exercise activity are well documented [52-54], both for the adult population [54] and in the pre-adult developmental phase [55]. However, evidence is emerging in the literature that for a small minority of individuals, excessive physical exercise can acquire the features of an addiction [12,56], characterized by feelings of loss of control, overtraining problems such as fatigue and sleep disturbances, and withdrawal symptoms such as restlessness, sadness, and irritability [57]. In light of these considerations, and the psychophysical damage associated with this condition, the study of the mechanisms involved in the development and maintenance of this unhealthy form of exercise acquires great clinical and practical relevance. Given this framework, the present research analyzed the interaction between alexithymia, body image concerns, and self-esteem in contributing to exercise addiction among regular exercisers.

First, our results showed a significant and positive influence of alexithymia on exercise addiction, concurring with previous research [58,59]. This is consistent with other evidence highlighting the role of alexithymia and, more generally, emotional dysregulation in facilitating addictive behaviors, which may become dysfunctional strategies to cope with painful emotions (see Morie et al. [18] for a review). Indeed, given their lack of emotional awareness, individuals with high levels of alexithymia tend to have difficulty in managing their affect $[14,60,61]$, and engaging in addictive behavior may become a dysfunctional strategy to cope with painful emotion [62,63]. Consistently, the theory of affect regulation [64] suggests that physical activity may lead to improvements in positive moods and decreases in negative ones (anxiety, irritability, and guilt). Therefore, some individuals may consider exercise as a means of coping with stress, to the point of becoming addicted to it $[56,64-66]$. Furthermore, the findings of the present study showed a significant positive association between alexithymia and body image concerns. 
Consistently, previous evidence has found that poor emotional expression is related to higher levels of body dissatisfaction, among both clinical [27] and nonclinical samples [28]. One of the characteristics of alexithymia is that individuals have difficulty in understanding their own affective experiences and/or the association between emotional states and somatic manifestations. This may lead to an excessive focus on physical components and body image distortions so as to avoid contact with the emotional experiences [28,67]. Our results also highlighted the significant and positive influence of body image concerns on exercise addiction, determining a total mediation in the relationship between alexithymia and exercise addiction. Consistent with these data, significant and positive associations between negative body image and pathological exercise behaviors have previously been found $[42,68]$.

This can be understood in light of the great potential that exercise has to modify the characteristics of the body (see Marques et al. [69] for a review). Therefore, body dissatisfaction may lead to morbid exercise, both through negative reinforcement (e.g., guilt by individuals for wasting opportunities to improve their appearance when skipping workouts) and positive reinforcement (e.g., a more toned body) [70]. Therefore, by integrating and enriching the existing evidence, data from the present research suggested that the total effect of alexithymia on exercise addiction did not occur directly, but manifested itself indirectly through the increase in dissatisfaction related to an individual's own body image, which resulted in morbid exercise, plausibly interpretable as a dysfunctional coping strategy [65]. However, the results also showed the relevant influence of self-esteem in this indirect path, so that as the score of self-esteem increased, the effect of alexithymia on body image concerns diminished to become insignificant. Such data are consistent with a previous study that highlighted an inverse relationship between self-esteem and negative perceptions of body image [28], and further corroborate the existing evidence relating to the core role of self-esteem in psychological wellbeing (e.g., [71]) and as a protective factor for mental health (e.g., [72]).

Additionally, age was found to be a significant confounding variable in the model, given its effect on exercise addiction. More specifically, older participants reported higher levels of morbid physical activity. These data add to the extant literature that currently reports conflicting results, sometimes identifying higher levels of exercise addiction among young people, while other studies report no difference based on age (e.g., [73,74]). Further studies are needed in order to investigate this aspect.

The present study has some limitations, which should be noted when interpreting its findings. First, the cross-sectional design of this research hinders the inference of causal links between the variables under examination. Furthermore, the implementation of the moderated mediation model did not consider the bidirectionality of the associations between the variables. Although the hypothesized links were based on a solid body of pre-existing literature, the present data only provide preliminary support for the observed relationships. Future longitudinal research is needed in order to test the relationships empirically, as well as considering the possibility of bidirectionality in the association between the variables, and further enriching the model by exploring the roles of other promising factors in the field of addiction and mental health, such as attachment (e.g., [75]), family functioning (e.g., [76]), and dissociation (e.g., [61]), to name but a few. Furthermore, data were collected online, and this could limit the generalizability of the study (for example, with respect to exercisers who did not have internet access). The relatively small sample size should also be noted when interpreting the study's outcomes. Moreover, the imbalance concerning some demographic variables (e.g., gender, relationship status, occupation) did not allow reliable evaluation of their relationship with the risk/protective factors included in the model, or of the relationships between them. Therefore, a more indepth study utilizing a larger and more balanced sample, recruited with a more extensive and representative sampling method, is needed for future research, in order to provide a more complete picture of these results. In addition, no information was collected on the level of physical activity (e.g., recreational or competitive). Future research could 
explore the influence of this variable on the hypothesized moderated mediation model. Finally, self-report measures were used, and this exposed the possibility of some bias (e.g., social desirability). Integration of other kinds of measure (e.g., structural interviews) following a multimethod approach could be important in future research to overcome this limitation. Therefore, in light of these limitations, the results must be generalized with caution, and studies with more representative samples of the national population, with a better distribution for demographic variables (e.g., gender, occupational status, relational status, etc.), are necessary. Further research is also needed examining the level/mode of sport (competitive/non-competitive; individual/team sport), with a longitudinal design and an integrated multimethod collection of further variables of interest, in order to obtain a clearer picture. On the other hand, the present research offers preliminary data that provide useful indications concerning the protective value of high levels of self-esteem against exercise addiction, as well as the importance of considering the potential risks that could be associated with alexithymia and body image concern.

\section{Conclusions}

As with other addictions, exercise addiction influences individuals in their daily lives, resulting in a loss of control and psychophysical damage [70]. Given the significant impairment in the lives of affected individuals, increasing research has focused on risk factors and antecedents for exercise addiction (e.g., [77]). Within this framework, the present study explored the positive relationships between alexithymia, body image concerns, and exercise addiction, but also confirmed the important protective role of self-esteem. These findings provide wider knowledge and insight regarding the variables associated with exercise addiction, and may have important clinical implications-for example, by orienting preventive activities among regular exercisers, as well as addressing tailored treatments for addicted individuals.

Author Contributions: Conceptualization, A.G.; methodology, A.G. and E.T.; formal analysis, A.G. and E.T.; data curation, A.G. and C.P.; writing—original draft preparation, A.G., E.T., C.P. and M.D.G.; writing - review and editing, A.G., E.T., C.P. and M.D.G.; supervision, A.G. and M.D.G. All authors have read and agreed to the published version of the manuscript.

Funding: This research received no external funding.

Institutional Review Board Statement: The study was conducted in accordance with the guidelines of the Declaration of Helsinki, and approved by the Ethics Committee of Integrated Psychodynamic Psychotherapy Institute (IPPI; protocol code 004/2021).

Informed Consent Statement: Informed consent was obtained from all subjects involved in the study.

Data Availability Statement: The data presented in this study are available on request from the corresponding author. The data are not publicly available, for reasons of privacy.

Conflicts of Interest: The authors declare no conflict of interest.

\section{References}

1. World Health Organization. WHO Guidelines on Physical Activity and Sedentary Behavior. 2020. Available online: https: //www.who.int/publications/i/item/9789240015128 (accessed on 6 October 2021).

2. Reiner, M.; Niermann, C.; Jekauc, D.; Woll, A. Long-term health benefits of physical activity-A systematic review of longitudinal studies. BMC Public Health 2013, 13, 2-9. [CrossRef] [PubMed]

3. World Health Organization. Physical Activity; World Health Organization: Geneva, Switzerland, 2020. Available online: https://www.who.int/news-room/fact-sheets/detail/physical-activity (accessed on 6 October 2021).

4. Venturella, F.; Cancellieri, G.; Liga, A. Rilevazione statistica della diffusione dei fenomeni di binge drinking, drunkoressia e gambling tra gli adolescenti palermitani. Mission 2017, 48, 47-51. [CrossRef]

5. Szabo, A.; Griffiths, M.D.; de La Vega Marcos, R.; Mervó, B.; Demetrovics, Z. Methodological and conceptual limitations in exercise addiction research. Yale J. Biol. Med. 2015, 88, 303-308. [PubMed]

6. Lichtenstein, M.B.; Melin, A.K.; Szabo, A.; Holm, L. The prevalence of exercise addiction symptoms in a sample of national level elite athletes. Front. Sports Act. Living 2021, 3, 635418. [CrossRef] [PubMed]

7. Landolfi, E. Exercise addiction. Sports Med. 2012, 43, 111-119. [CrossRef] 
8. Griffiths, M. A 'components' model of addiction within a biopsychosocial framework. J. Subst. Use 2005, 10, 191-197. [CrossRef]

9. Terry, A.; Szabo, A.; Griffiths, M. The exercise addiction inventory: A new brief screening tool. Addict. Res. Theory 2004, 12, 489-499. [CrossRef]

10. Veale, D. Does primary exercise dependence really exist? In Exercise Addiction: Motivation for Participation in Sport and Exercise; Annett, J., Cripps, B., Steinberg, H., Eds.; British Psychological Society: Leicester, UK, 1995; pp. 1-5.

11. Freimuth, M.; Moniz, S.; Kim, S.R. Clarifying exercise addiction: Differential diagnosis, co-occurring disorders, and phases of addiction. Int. J. Environ. Res. Public Health 2011, 8, 4069-4081. [CrossRef]

12. Griffiths, M. Exercise addiction: A case study. Addict. Res. 1997, 5, 161-168. [CrossRef]

13. Sifneos, P.E. The prevalence of 'alexithymic' characteristics in psychosomatic patients. Psychother. Psychosom. 1973, 22, 255-262. [CrossRef]

14. Bagby, R.M.; Parker, J.D.; Taylor, G.J. The twenty-item Toronto Alexithymia Scale-I. Item selection and cross-validation of the factor structure. J. Psychosom. Res. 1994, 38, 23-32. [CrossRef]

15. Bagby, R.M.; Taylor, G.J.; Parker, J.D. The twenty-item Toronto Alexithymia Scale-II. Convergent, discriminant, and concurrent validity. J. Psychosom. Res. 1994, 38, 33-40. [CrossRef]

16. Taylor, G.J. Recent developments in alexithymia theory and research. Can. J. Psychiatry 2000, 45, 134-142. [CrossRef]

17. Dell'Arte, S.; Lenzo, V. Personality, exercise addiction and orthorexia. A research contribution. J. Clin. Child. Psychol. 2021, 3, 63-83. [CrossRef]

18. Morie, K.P.; Yip, S.W.; Nich, C.; Hunkele, K.; Carroll, K.M.; Potenza, M.N. Alexithymia and addiction: A review and preliminary data suggesting neurobiological links to reward/loss processing. Curr. Addict. Rep. 2016, 3, 239-248. [CrossRef] [PubMed]

19. Lafollie, D. Detection of high-risk personalities in risky sports. L'encephale 2007, 33, 135-141. [CrossRef]

20. Hamidi, S.; Rostami, R.; Farhoodi, F.; Abdolmanafi, A. A study and comparison of Alexithymia among patients with substance use disorder and normal people. Procedia-Soc. Behav. Sci. 2010, 5, 1367-1370. [CrossRef]

21. de Berardis, D.; D’Albenzio, A.; Gambi, F.; Sepede, G.; Valchera, A.; Conti, C.M.; Fulcheri, M.; Cavuto, M.; Ortolani, C.; Salerno, R.M.; et al. Alexithymia and its relationships with dissociative experiences and Internet addiction in a nonclinical sample. Cyberpsychol. Behav. Soc. Netw. 2009, 12, 67-69. [CrossRef] [PubMed]

22. Parker, J.D.; Wood, L.M.; Bond, B.J.; Shaughnessy, P. Alexithymia in young adulthood: A risk factor for pathological gambling. Psychother. Psychosom. 2004, 74, 51-55. [CrossRef] [PubMed]

23. Orsolini, L. Unable to describe my feelings and emotions without an addiction: The interdependency between alexithymia and addictions. Front. Psychiatry 2020, 11, 543346. [CrossRef] [PubMed]

24. Manfredi, P.; Gambarini, A. Exercise addiction and alexithymia. J. Psychol. Behav. Sci. 2015, 3, 61-70. [CrossRef]

25. Allegre, B.; Souville, M.; Noel-Jorand, M.C.; Pellegrin, L.; Therme, P. Intensive physical activity and alexithymia: Results from swimmers' discourse analysis. Psychol. Rep. 2007, 100, 1129-1139. [CrossRef] [PubMed]

26. Iacolino, C.; Pellerone, M.; Formica, I.; Concetta Lombardo, E.M.; Tolini, G. Alexithymia, body perception and dismorphism: A study conducted on sportive and non-sportive subjects. Clin. Neuropsychiatry 2017, 14, 400-406.

27. Fenwick, A.S.; Sullivan, K.A. Potential link between body dysmorphic disorder symptoms and alexithymia in an eating-disordered treatment-seeking sample. Psychiatry Res. 2011, 189, 299-304. [CrossRef]

28. de Berardis, D.; Serroni, N.; Campanella, D.; Carano, A.; Gambi, F.; Valchera, A.; Conti, C.; Sepede, G.; Caltabiano, M.; Pizzorno, A.M.; et al. Alexithymia and its relationships with dissociative experiences, body dissatisfaction and eating disturbances in a non-clinical female sample. Cognit. Ther. Res. 2009, 33, 471-479. [CrossRef]

29. Corazza, O.; Simonato, P.; Demetrovics, Z.; Mooney, R.; van de Ven, K.; Roman-Urrestarazu, A.; Rácmolnár, L.; de Luca, I.; Cinosi, E.; Santacroce, R.; et al. The emergence of exercise addiction, body dysmorphic disorder, and other image-related psychopathological correlates in fitness settings: A cross sectional study. PLoS ONE 2019, 14, e0213060. [CrossRef] [PubMed]

30. Fortes, L.D.S.; Neves, C.M.; Filgueiras, J.F.; Almeida, S.S.; Ferreira, M.E.C. Body dissatisfaction, psychological commitment to exercise and eating behavior in young athletes from aesthetic sports. Rev. Bras. Cineantropometria Desempenho Hum. 2013, 15, 695-704.

31. Klein, D.A.; Bennett, A.S.; Schebendach, J.; Foltin, R.W.; Devlin, M.J.; Walsh, B.T. Exercise "addiction" in anorexia nervosa: Model development and pilot data. CNS Spectr. 2004, 9, 531-537. [CrossRef]

32. Blaydon, M.J.; Linder, K.J.; Kerr, J.H. Metamotivational characteristics of exercise dependence and eating disorders in highly active amateur sport participants. Pers. Individ. Differ. 2004, 36, 1419-1432. [CrossRef]

33. Gilbert, N.; Meyer, C. Fear of negative evaluation and the development of eating psychopathology: A longitudinal study among nonclinical women. Int. J. Eat. Disord. 2005, 37, 307-312. [CrossRef] [PubMed]

34. Grilo, C.M.; Masheb, R.M. Correlates of body image dissatisfaction in treatment-seeking men and women with binge eating disorder. Int. J. Eat. Disord. 2005, 38, 162-166. [CrossRef] [PubMed]

35. O'Dea, J.A. Body image and self-esteem. In Encyclopedia of Body Image and Human Appearance; Cash, T.F., Ed.; Elsevier Academic Press: Norfolk, VA, USA, 2012; pp. 141-147.

36. Ahadzadeh, A.S.; Rafik-Galea, S.; Alavi, M.; Amini, M. Relationship between body mass index, body image, and fear of negative evaluation: Moderating role of self-esteem. Health Psychol. Open 2018, 5, 205510291877425. [CrossRef] [PubMed]

37. Dunaev, J.L.; Schulz, J.L.; Markey, C.N. Cosmetic surgery attitudes among midlife women: Appearance esteem, weight esteem, and fear of negative appearance evaluation. J. Health Psychol. 2018, 23, 59-66. [CrossRef] [PubMed] 
38. Junghans-Rutelonis, A.N.; Suorsa, K.I.; Tackett, A.P. Self-esteem, self-focused attention, and the mediating role of fear of negative evaluation in college students with and without asthma. J. Am. Coll. Health 2015, 63, 554-562. [CrossRef]

39. Jankauskiene, R.; Baceviciene, M. Body image concerns and body weight overestimation do not promote healthy behaviour: Evidence from adolescents in Lithuania. Int. J. Environ. Res. 2019, 16, 864. [CrossRef]

40. Paxton, S.J.; Eisenberg, M.E.; Neumark-Sztainer, D. Prospective predictors of body dissatisfaction in adolescent girls and boys: A five-year longitudinal study. Dev. Psychol. 2006, 42, 888-899. [CrossRef] [PubMed]

41. Gori, A.; Topino, E.; Griffiths, M.D. Protective and risk factors in exercise addiction: A series of moderated mediation analyses. Int. J. Environ. Res. Public Health 2021, 18, 9706. [CrossRef] [PubMed]

42. Griffiths, M.D.; Szabo, A.; Terry, A. The exercise addiction inventory: A quick and easy screening tool for health practitioners. Br. J. Sports Med. 2005, 39, e30. [CrossRef] [PubMed]

43. Gori, A.; Topino, E.; Griffiths, M. A screening tool for exercise addiction: The psychometric properties of the Italian Exercise Addiction Inventory. Int. J. Ment. Health Addict. 2021, in press.

44. Bressi, C.; Taylor, G.; Parker, J.; Bressi, S.; Brambilla, V.; Aguglia, E.; Allegranti, I.; Bongiorno, A.; Giberti, F.; Bucca, M.; et al. Cross validation of the factor structure of the 20-item Toronto Alexithymia Scale: An Italian multicenter study. J. Psychosom. Res. 1996, 41, 551-559. [CrossRef]

45. Littleton, H.L.; Axsom, D.; Pury, C.L. Development of the Body Image Concern Inventory. Behav. Res. Ther. 2005, 43, 229-241. [CrossRef]

46. Luca, M.; Giannini, M.; Gori, A.; Littleton, H. Measuring dysmorphic concern in Italy: Psychometric properties of the Italian Body Image Concern Inventory (I-BICI). Body Image 2011, 8, 301-305. [CrossRef] [PubMed]

47. Rosenberg, M. Rosenberg Self-Esteem Scale (RSE). PsycTESTS Dataset 1965, 61, 52.

48. Prezza, M.; Trombaccia, F.R.; Armento, L. La scala dell'autostima di Rosenberg: Traduzione e validazione Italiana [The Rosenberg Self-Esteem Scale: Italian translation and validation]. Giunti Organ. Spec. 1997, 223, 35-44.

49. Cohen, J. Statistical Power Analysis for the Behavioral Sciences, 2nd ed.; Lawrence Erlbaum: Hillsdale, NJ, USA, 1988.

50. Hayes, A.F. Introduction to Mediation, Moderation, and Conditional Process Analysis Second Edition: A Regression-Based Approach; Guilford Press: New York, NY, USA, 2018.

51. Wayne, S.J.; Lemmon, G.; Hoobler, J.M.; Cheung, G.W.; Wilson, M.S. The ripple effect: A spillover model of the detrimental impact of work-family conflict on job success. J. Organ. Behav. 2017, 38, 876-894. [CrossRef]

52. Biddle, S.J.; Mutrie, N.; Gorely, T.; Faulkner, G. Psychology of Physical Activity: Determinants, Well-Being and Interventions; Routledge: New York, NY, USA, 2021. [CrossRef]

53. Warburton, D.E.; Bredin, S.S. Reflections on physical activity and health: What should we recommend? Can. J. Cardiol. 2016, 32, 495-504. [CrossRef]

54. Warburton, D.E.; Nicol, C.W.; Bredin, S.S. Health benefits of physical activity: The evidence. CMAJ 2006, 174, 801-809. [CrossRef]

55. Piko, B.F.; Keresztes, N. Physical activity, psychosocial health and life goals among youth. J. Community Health 2006, 31, 136-145. [CrossRef]

56. Szabo, A. Exercise Addiction: A Symptom or a Disorder; Nova Science Publishers: Hauppauge, NY, USA, 2010.

57. Hausenblas, H.A.; Schreiber, K.; Smoliga, J.M. Addiction to exercise. BMJ 2017, 357, j1745. [CrossRef]

58. Woodman, T.; Cazenave, N.; Le Scanff, C. Skydiving as emotion regulation: The rise and fall of anxiety is moderated by alexithymia. J. Sport Exerc. Psychol. 2008, 30, 424-433. [CrossRef] [PubMed]

59. Van Landeghem, C.; Jakobson, L.S.; Keough, M.T. Risk of exercise dependence in university students: A subtyping study utilizing latent profile analysis. Psychol. Sport Exerc. 2019, 45, 101575. [CrossRef]

60. Pellerone, M.; Cascio, M.I.; Costanzo, G.; Gori, A.; Pace, U.; Craparo, G. Alexithymia and psychological symptomatology: Research conducted on a non-clinical group of Italian adolescents. Int. J. Cult. Ment. 2017, 10, 300-309. [CrossRef]

61. Gori, A.; Topino, E.; Craparo, G.; Bagnoli, I.; Caretti, V.; Schimmenti, A. A comprehensive model for gambling behaviors: Assessment of the factors that can contribute to the vulnerability and maintenance of gambling disorder. J. Gambl. Stud. 2021. Online first. [CrossRef]

62. Craparo, G.; Magnano, P.; Zapparrata, M.V.; Gori, A.; Costanzo, G.; Pace, U.; Pellerone, M. Coping, attachment style and resilience: The mediating role of alexithymia. Mediterr. J. Clin. Psychol. 2018, 6, 1-30. [CrossRef]

63. Caretti, V.; Gori, A.; Craparo, G.; Giannini, M.; Iraci-Sareri, G.; Schimmenti, A. A new measure for assessing substance-related and addictive disorders: The Addictive Behavior Questionnaire (ABQ). J. Clin. Med. 2018, 7, 194. [CrossRef]

64. Hamer, M.; Karageorghis, C.I. Psychobiological mechanisms of exercise dependence. Sports Med. 2007, 37, 477-484. [CrossRef]

65. Berczik, K.; Szabó, A.; Griffiths, M.D.; Kurimay, T.; Kun, B.; Urbán, R.; Demetrovics, Z. Exercise addiction: Symptoms, diagnosis, epidemiology, and etiology. Subst. Use Misuse 2012, 47, 403-417. [CrossRef]

66. Szabo, A. The impact of exercise deprivation on well-being of habitual exercises. Aust. J. Sci. Med. Sport 1995, 27, 68-75. [PubMed]

67. Montebarocci, O.; Codispoti, M.; Surcinelli, P.; Franzoni, E.; Baldaro, B.; Rossi, N. Alexithymia in female patients with eating disorders. Eat. Weight Disord. 2006, 11, 14-21. [CrossRef]

68. Tornero-Quiñones, I.; Sáez-Padilla, J.; Castillo Viera, E.; Garcia Ferrete, J.J.; Sierra Robles, A. Risk of dependence on sport in relation to body dissatisfaction and motivation. Sustainability 2019, 11, 5299. [CrossRef]

69. Marques, A.; Peralta, M.; Sarmento, H.; Loureiro, V.; Gouvei, A.É.R.; de Matos, M.G. Prevalence of risk for exercise dependence: A systematic review. Sports Med. 2019, 49, 319-330. [CrossRef] [PubMed]

70. Szabo, A.; Demetrovics, Z.; Griffiths, M.D. Morbid exercise behavior: Addiction or psychological escape? In The Exercise Effect on Mental Health: Neurobiological Mechanisms; Budde, H., Wegner, M., Eds.; Routledge: New York, NY, USA, 2018 ; pp. $277-311$. 
71. Pandey, R.; Tiwari, G.K.; Parihar, P.; Rai, P.K. Positive, not negative, self-compassion mediates the relationship between self-esteem and well-being. Psychol. Psychother. 2021, 94, 1-15. [CrossRef] [PubMed]

72. Brausch, A.M.; Decker, K.M. Self-esteem and social support as moderators of depression, body image, and disordered eating for suicidal ideation in adolescents. J. Abnorm. Child. Psychol. 2014, 42, 779-789. [CrossRef]

73. Reche, C.; de Francisco, C.; Martínez-Rodríguez, A.; Ros-Martínez, A. Relationship among sociodemographic and sport variables, exercise dependence, and burnout: A preliminary study in athletes. Ann. Psychol. 2018, 34, 398-404. [CrossRef]

74. Mayolas-Pi, C.; Simon-Grima, J.; Peñarrubia-Lozano, C.; Munguía-Izquierdo, D.; Moliner- Urdiales, D.; Legaz-Arrese, A. Exercise addiction risk and health in male and female amateur endurance cyclists. J. Behav. Addict. 2016, 6, 74-83. [CrossRef]

75. Giannini, M.; Gori, A.; De Sanctis, E.; Schuldberg, D. Attachment in psychotherapy: Psychometric properties of the Psychological Treatment Inventory Attachment Styles Scale (PTI-ASS). J. Psychother. Integr. 2011, 21, 363-381. [CrossRef]

76. Cacioppo, M.; Barni, D.; Correale, C.; Mangialavori, S.; Danioni, F.; Gori, A. Do attachment styles and family functioning predict adolescents' problematic internet use? A relative weight analysis. J. Child. Fam. Stud. 2019, 28, 1263-1271. [CrossRef]

77. Bircher, J.; Griffiths, M.D.; Kasos, K.; Demetrovics, Z.; Szabo, A. Exercise addiction and personality: A two-decade systematic review of the empirical literature (1995-2015). Balt. J. Sport Health Sci. 2017, 3, 19-33. [CrossRef] 